\title{
Breastfeeding Knowledge, Attitude and Intention among Female Young Adults in Ibadan, Nigeria
}

\author{
Oluwatosin Leshi*, Folake 0. Samuel, Marian 0. Ajakaye \\ Department of Human Nutrition, Faculty of Public Health, University of Ibadan, Ibadan, Nigeria \\ Email: "ttlesh@gmail.com
}

Received 8 October 2015; accepted 15 January 2016; published 18 January 2016

Copyright (C) 2016 by authors and Scientific Research Publishing Inc.

This work is licensed under the Creative Commons Attribution International License (CC BY). http://creativecommons.org/licenses/by/4.0/

\section{Open Access}

\begin{abstract}
Background: The decision to breastfeed is largely dependent on mothers' breastfeeding knowledge and attitude which are usually formed in their adolescence and early adulthood. It is important to focus research on female young adult who are at the verge of stepping into motherhood. Methods: The breastfeeding knowledge, attitude and intention of 457 female young adults in Ibadan, Nigeria were assessed through validated breastfeeding knowledge, attitude and intention scales. Results: Majority (87.5\%) of the respondents had never given birth and $\mathbf{7 4 . 6 \%}$ had previously participated in breastfeeding discussions. About half $(52.1 \%)$ knew breastfeeding should be initiated within one hour of birth while $49.9 \%$ reported that pre-lacteal feed should not be given to newborn babies. Correct definition of exclusive breastfeeding was given by two-third of the respondents and three-quarter specified that breastfeeding was beneficial to both mother and child. Overall $43.1 \%$ of the respondents had good breastfeeding knowledge. About $80 \%$ of the respondents agreed that breastfeeding should be initiated within one hour after delivery, $37.8 \%$ were of the opinion that breast milk only was not sufficient for infants in the first 6 months of life while about half of the respondents agreed that water should be introduced to babies before 6 months. In all, $53.8 \%$ had positive attitude towards breastfeeding. Only a third of the respondents had good breastfeeding intention although $\mathbf{9 0 . 6 \%}$ claimed that they intended to breastfeed. Only $35.9 \%$ indicated to have known all it took to breastfeed and $54 \%$ intended to introduce breastmilk within 1 hour of birth while $60 \%$ had the intention of breastfeeding exclusively. There was significant association between breastfeeding knowledge and attitude as well as breastfeeding knowledge and intention. Conclusion: Female young adult demonstrated relatively fair breastfeeding knowledge and attitude but poor intention to breastfeed. Intervention to improve breastfeeding knowledge, attitude and intention of this population is recommended.
\end{abstract}

\footnotetext{
"Corresponding author.
}

How to cite this paper: Leshi, O., Samuel, F.O. and Ajakaye, M.O. (2016) Breastfeeding Knowledge, Attitude and Intention among Female Young Adults in Ibadan, Nigeria. Open Journal of Nursing, 6, 11-23. 


\section{Keywords}

\section{Breastfeeding, Knowledge, Attitude, Intention, Young Adult}

\section{Introduction}

Malnutrition contributes to more than half of global under-five childhood deaths and well over two-thirds of these deaths which occur in the first year of life are often associated with inappropriate feeding practices [1]. Breastfeeding is regarded as the most cost-effective public health measure that significantly impacts infant morbidity and mortality in developing countries [2] [3]. The decision to breastfeed is influenced by both the knowledge and attitude of mothers towards breastfeeding. This decision is however, probably formed as early as adolescence [4] and perhaps, also in early adulthood. Young adults are the age group in the population which can easily be influenced by peers, lifestyle, and sociocultural beliefs. The current choices of the youth have been reported to affect their future reproductive practice [5] [6]. Breastfeeding intention of future parents could be greatly influenced by their current knowledge and attitude towards breastfeeding. Following this reasoning, Marrone and colleagues had pointed out the need to understand young adults' breastfeeding knowledge and attitude [7]. This is because attitude which eventually influences practice toward breastfeeding is formed early in life [8]. Several studies have investigated the breastfeeding knowledge and attitude among adolescents and young adults, some of which are secondary school students [9], adolescent mothers [10] [11] and university students [7] [12]-[15]. However, there is a dearth of similar research in Nigeria focusing on female young adults who are at the verge of stepping into motherhood. Yet this is important in addressing childhood malnutrition through optimum breastfeeding of mothers especially in Nigeria, where suboptimal breastfeeding practices are widespread. The aim of this study is therefore to assess breastfeeding knowledge, attitudes and intention of female young adults in Ibadan, Nigeria.

\section{Methods}

\subsection{Study Design and Sample}

This cross-sectional study was conducted among young female adults who had just recently graduated from tertiary institutions in Nigeria, and enrolled into the mandatory National Youth Service Corps (NYSC) scheme in Ibadan, the capital city of Oyo State, Nigeria. The NYSC scheme was set up in 1973 by the Nigerian government to involve the country's graduates in the development of the country. Graduates from tertiary institutions such as, universities, polytechnics, and monotechnics who are not more than 30 years of age are required to take part in the compulsory National Youth Service program for one year. The aim of the program is to ensure national integration and unity among youths from various region of the country, and a means of inculcating the spirit of selfless service. The "corpers" as the NYSC members are commonly called, are posted to communities far from their community of origin thereby exposing them to people of other ethnicity, language and socialcultural characteristics.

The metropolitan area of Ibadan comprises of five Local Government Areas (LGAs) of which three (Ibadan North, Ibadan South-East, and Ibadan South-West Local Government Areas) were randomly selected for the study. A total of 457 out of a total of 1200 female corpers were recruited based on their willingness to participate in the study. Questionnaires were administered to them at their weekly Community Development Service (CDS) meetings at the LGA headquarters.

\subsection{Instruments}

From August to October 2014, a semi-structured, self-administered questionnaire was used to obtain information from the study participants.

The process of questionnaire development was guided by review of literature on breastfeeding knowledge, attitude and intention [7] [9] [12]-[16] from which questions and scales were constructed which are culturally appropriate to the study population. The questionnaire was divided into four sections; the first section was designed to elicit the socio-demographic information, this included the age, state of origin, course studied, religion, 
marital status, intended age of marriage, and if participant had ever given birth. The second section elicited information on breastfeeding knowledge of the respondents. This included questions on previous participation in breastfeeding discussion, breastfeeding initiation, duration, mode of breastfeeding, definition of exclusive breastfeeding and colostrum, benefits of breastfeeding and breastfeeding cessation. The third section covered the attitude of respondents towards breastfeeding. The questions were optioned to be "strongly agree", "agree", "neutral", "disagree" and "strongly agree". This included questions on infant feeding practice, comparison of breast milk to infant food and public embarrassment of breastfeeding. The fourth section was to elicit information on breastfeeding intention of the respondents. This included questions on intended age to carry out infant feeding practices for child starting from initiation of breast milk to the cessation, intention of respondents to breastfeed later in future, influence of relatives/families support on breastfeeding and cultural barrier on breastfeeding. The questionnaire was pilot-tested among 40 female corps members outside the study location.

Breastfeeding knowledge scale was constructed and consisted of 12 point score. Participants with correct and incorrect responses were score 1 and 0 respectively thus allowing for a total score of 12 (ranging from 0 to 12). The Cronbach's alpha of the knowledge scale was 0.78 . The attitude scale consisted of 10 point attitude statements with responses ranging from either agreed or disagreed. The breastfeeding intention was assessed through a 10 point questions with potential responses of "Yes", "No" and "Undecided". The Cronbach's alpha for attitude and intention components were 0.75 and 0.84 respectively. Participants with score of 8 and above in the breastfeeding knowledge scale were considered to indicate a good breastfeeding knowledge, while, those with score below 8 were regarded to have poor knowledge. From the attitude and intention scales, on the other hand participants with score below 6 were regarded to have negative attitude and poor intention toward breastfeeding while positive attitude and good intention to breastfeed were defined as participants scores of 6 and above respectively on the breastfeeding attitude and intention scale.

\subsection{Data Analysis}

Data were entered into Epidata version 3.1, cleaned, and then analyzed with IBM SPSS 20.0. Descriptive statistics were implored to describe the socio-demographics information, breastfeeding knowledge, attitude and intention of the respondents. To assess the internal consistency and reliability, Cronbach's alpha was calculated for knowledge, attitude and knowledge scales. Chi-square test was used to assess the relationship between breastfeeding knowledge, attitude and intention with level of significance set at 0.05 .

\subsection{Ethical Issues}

Ethical approval was sought from the University of Ibadan/University College Hospital Ethics Committee. Approval was also sought from the relevant authorities of the NYSC scheme. Respondent's informed consent was obtained after explaining the purpose of the research. Participation in the study was entirely voluntary and no financial inducement whatsoever was involved. Voluntary withdrawal at any stage of interaction was guaranteed for all respondents. All information was handled with strict confidentiality.

\section{Results}

\section{Socio-Demographic Characteristics}

Table 1 presents the socio-demographic characteristics of the 457 study participants. Three-quarter of the Youth corps members were Yoruba, about $12.3 \%$ were Igbo, and $0.8 \%$ were Hausa while $11.2 \%$ of the female corps members belonged to the minority ethnic groups. Most (81.2\%) of the respondents were Christian while $18.8 \%$ were Muslim. The mean age was $25( \pm 3.0)$ years with $63.3 \%$ and $35.4 \%$ within $20-25$ years and 26 - 30 years respectively. About $70 \%$ of the female corps members were single while $17.1 \%$ were married; about half of the respondents intended to marry within 1 year after the interview. Although majority (87.5\%) of the female corps members had never given birth, three-quarter of them had been involved in formal or informal breastfeeding discussion before. About $60 \%$ of the respondents became aware of breastfeeding through the social media, about $25 \%$ through family and friends, and 20.6\% at health facilities. Majority (73.5\%) agreed that fathers have a role to play in ensuring optimum breastfeeding.

The knowledge of the female young adults in the current study toward breastfeeding deviated from the current international recommendations. As shown in Table 2, a little more than half of the participants knew that mothers 
Table 1. Socio-demographic characteristics of the respondents.

\begin{tabular}{|c|c|c|}
\hline Variables & Frequency & Percentage \\
\hline \multicolumn{3}{|l|}{ Ethnicity } \\
\hline Yoruba & 346 & 75.7 \\
\hline Igbo & 56 & 12.3 \\
\hline Hausa & 4 & 0.8 \\
\hline Minority group & 51 & 11.2 \\
\hline \multicolumn{3}{|l|}{ Religion } \\
\hline Muslim & 86 & 18.8 \\
\hline Christian & 371 & 81.2 \\
\hline \multicolumn{3}{|l|}{ Age in years $(n=395)$} \\
\hline Less than 20 years & 2 & 0.5 \\
\hline 20 - 25 years & 250 & 63.3 \\
\hline 26 - 30 years & 138 & 34.9 \\
\hline Greater than 30 years & 5 & 1.3 \\
\hline \multicolumn{3}{|c|}{ Mean $(S D)=25( \pm 3)$ years } \\
\hline \multicolumn{3}{|l|}{ Marital status } \\
\hline Single & 323 & 70.7 \\
\hline Engaged & 56 & 12.3 \\
\hline Married & 78 & 17.1 \\
\hline \multicolumn{3}{|c|}{ Intended year to marry $(n=234)$} \\
\hline Less than 1 year & 30 & 12.8 \\
\hline About 1 year & 111 & 47.4 \\
\hline About 2 years & 52 & 22.2 \\
\hline About 3 - 4 years & 41 & 17.5 \\
\hline \multicolumn{3}{|l|}{ Median = 1 year } \\
\hline \multicolumn{3}{|l|}{ Ever given birth } \\
\hline Yes & 57 & 12.5 \\
\hline No & 400 & 87.5 \\
\hline \multicolumn{3}{|c|}{ Ever involved in any formal or informal breastfeeding discussion } \\
\hline Yes & 341 & 74.6 \\
\hline No & 116 & 25.4 \\
\hline \multicolumn{3}{|l|}{ Source of information } \\
\hline Social media & 276 & 60.4 \\
\hline Family/friends & 115 & 25.2 \\
\hline Religious places & 28 & 6.1 \\
\hline Medical places & 94 & 20.6 \\
\hline Seminar & 20 & 4.4 \\
\hline Total & 457 & 100 \\
\hline
\end{tabular}


Table 2. Breastfeeding knowledge of the female corpers.

\begin{tabular}{|c|c|c|}
\hline Variable & Frequency & Percentage \\
\hline \multicolumn{3}{|l|}{ Initiation of breastfeeding by the mother } \\
\hline Within 1 hour after birth & 238 & 52.1 \\
\hline After 1 hour of delivery & 71 & 15.5 \\
\hline Don’t know & 148 & 32.4 \\
\hline \multicolumn{3}{|l|}{ Feeding of pre-lacteal liquid } \\
\hline Yes & 229 & 50.1 \\
\hline No & 192 & 42.0 \\
\hline Don’t know & 36 & 7.9 \\
\hline \multicolumn{3}{|l|}{ Knowledge of colostrum } \\
\hline Yes & 175 & 38.3 \\
\hline No & 282 & 61.7 \\
\hline \multicolumn{3}{|l|}{ Description of colostrum $(n=175)$} \\
\hline Correct description & 58 & 33.1 \\
\hline Wrong description & 117 & 66.9 \\
\hline \multicolumn{3}{|c|}{ Only breast milk is sufficient for infants $n$ the first 6 months } \\
\hline Yes & 317 & 69.4 \\
\hline No & 140 & 30.7 \\
\hline \multicolumn{3}{|l|}{ Introduction of water to the infant } \\
\hline Before 6 months & 135 & 29.5 \\
\hline 6 months and above & 211 & 46.2 \\
\hline Don’t know when to introduce water & 111 & 24.3 \\
\hline \multicolumn{3}{|l|}{ Definition of exclusive breastfeeding } \\
\hline Correctly defined & 302 & 66.1 \\
\hline Incorrectly defined & 128 & 28.0 \\
\hline Don't know the definition & 27 & 5.9 \\
\hline \multicolumn{3}{|c|}{$\begin{array}{l}\text { Complete covering of the nipples and its surroundings is one of } \\
\text { the appropriate positioning for breastfeeding }\end{array}$} \\
\hline Yes & 337 & 73.7 \\
\hline No & 120 & 26.3 \\
\hline \multicolumn{3}{|c|}{ Women with small breast cannot produce sufficient breast milk } \\
\hline Yes & 53 & 11.6 \\
\hline No & 404 & 88.4 \\
\hline \multicolumn{3}{|l|}{ Benefit of breastfeeding } \\
\hline Only to mother & 6 & 1.3 \\
\hline only to baby & 100 & 21.9 \\
\hline Both mother and baby & 335 & 73.3 \\
\hline Not beneficial to mother and baby & 16 & 3.5 \\
\hline
\end{tabular}




\section{Continued}

The mode of breastfeeding a baby

At mothers will

As baby demands

As scheduled by mother

Don’t know

troduction of complementary food to the infants

Before 6 month

At 6 month

After 6 month

Don't know when to introduce complementary food

Cessation of breastfeeding by the mother expected

Before 24 months

24 months and above

Don't know

Median time for cessation $=12$ months

Total
4.4

75.3

7.4

12.9

3.4

54.9

100

should initiate breastfeeding within one hour of delivery, and 50.1\% thought that pre-lacteal liquids should be introduced to an infant in the first three days after delivery. Out of $38.3 \%$ of the respondents that indicated their knowledge of colostrum, only one-third gave the correct description of colostrum.

Correct definition of exclusive breastfeeding was given by two-thirds of the respondents and most of them specified that breastfeeding is beneficial to both mother and child. About $70 \%$ of the respondents believed that breast milk alone is sufficient for infant's growth in the first 6 months of life. Three out of 10 female corps members reported that water should be introduced to the infant before 6 months while less than half indicated the introduction of water after 6 months. It was however revealed that about one-third of the respondents indicated not have known when to introduce water to the infant. The correct definition of exclusive breastfeeding was given by two-third of the respondents and three-quarter specified that breastfeeding is beneficial to both the mother and the child.

The mode of breastfeeding indicated by most (75.3\%) of the respondents was as baby demands. About 55\% of the female corps members knew that complementary food should be introduced by 6 months. The median time indicated for breastfeeding cessation was 12 months; $61 \%$ indicated that breast milk should be ceased before 24 months while $19.4 \%$ indicated 24 months and beyond Overall, the mean knowledge score was $7.02 \pm 2.3$ out of a maximum score of 12 and about 6 out of 10 of the female corps members had poor breastfeeding knowledge.

Table 3 presented the participants attitude towards breastfeeding. While about $80 \%$ of the participants agreed that breastfeeding should be initiated within 1 hour of delivery, about $60 \%$ agreed that colostrum protect the infants from infections. Four out of 10 respondents were of the opinion that breast milk is not sufficient for the infant in the first 6 months of life. About half of the participants agreed that water should be introduced to babies before 6 months of life while 3 out of every 10 respondents were of the view that breastfeeding in the public is embarrassing. Seventy seven percent were of the opinion that breastfeeding is cheaper than formula feeding while about $74 \%$ disagreed that formula feeding is healthier than breastfeeding. About $56 \%$ disagreed that Herbs/herbal drinks are beneficial to the health of babies especially in the first 6 months. Three-quarter of the female corps members strongly disagreed that the size of breast determines the amount of breast milk produced by mother. Generally, a little more than half (53.8\%) of the participants have a positive attitude toward breastfeeding (Figure 1). 
Table 3. Breastfeeding attitude of respondents.

\begin{tabular}{|c|c|c|c|}
\hline Attitude statement & Agree (\%) & Neutral (\%) & Disagree (\%) \\
\hline A mother should breastfeed her baby within one hour of delivery & 78.8 & 9.4 & 11.8 \\
\hline Colostrum protects the baby from infections & 63.1 & 13.1 & 23.8 \\
\hline Breast milk only is not sufficient for a baby in the first 6 months of life & 37.8 & 10.7 & 51.4 \\
\hline Water should be given to a baby before six months of life & 49.4 & 16.6 & 33.9 \\
\hline $\begin{array}{l}\text { Herbs/herbal drinks are beneficial to the health of babies especially in } \\
\text { the first } 6 \text { months }\end{array}$ & 29.7 & 14.7 & 55.5 \\
\hline Breast milk is cheaper than infant formula & 77.0 & 5.0 & 18.0 \\
\hline Formula feeding is healthier than breastfeeding & 18.1 & 7.7 & 74.2 \\
\hline Breastfeeding in public is embarrassing therefore should be discouraged & 27.2 & 19.9 & 53.0 \\
\hline $\begin{array}{l}\text { The size of breast determines the amount of breast milk produced by } \\
\text { mother }\end{array}$ & 15.3 & 9.2 & 75.5 \\
\hline $\begin{array}{l}\text { Breastfeeding cannot be continued when semi solid or soft food is } \\
\text { introduced to a baby }\end{array}$ & 17.3 & 9.8 & 72.9 \\
\hline
\end{tabular}

Disagree = strongly disagree/Tend to disagree; Agree = strongly agree/Tend to agree.

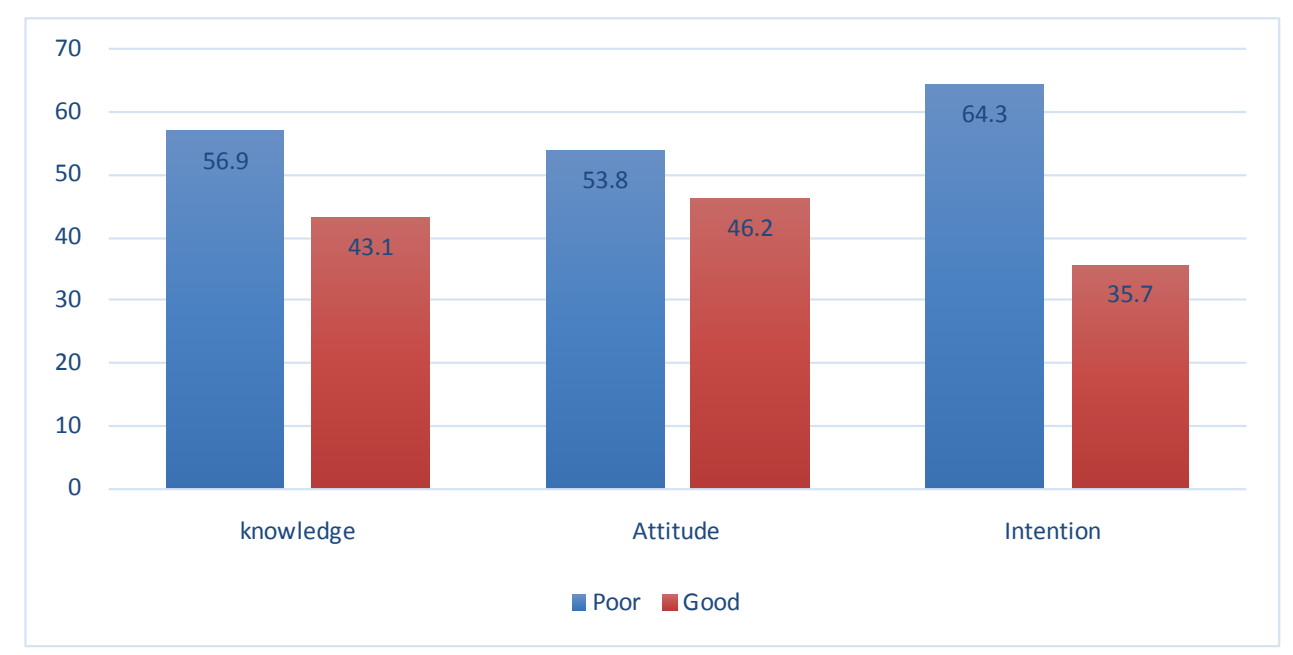

Figure 1. Breastfeeding knowledge, attitude and intention category of the respondents.

The intention of the study participants is as shown in Table 4. Although majority (90.6\%) of the respondents intended to breastfeed their future children, only 35.9\% indicated to have known all it requires to breastfeed while 55.4\% reported to have been well prepared for breastfeeding. Fifty four percent intended to introduce breastmilk within 1 hour of birth while $22.8 \%$ were yet to decide. The median age that the respondents intended to introduce water to their future children is 4 months with one-third intended to introduce water to their infants before 6 months of life, 40.9\% from 6 months and 25.8\% were yet to decide. About 60\% intended to breastfeed exclusively while $9 \%$ were yet to decide. Four out of 10 respondents indicated not have decided on when to introduce complementary food but only about $2 \%$ indicated less than 6 months. Overall, the breastfeeding intention of the female young adults in the current study was found to be poor (Figure 1). Table 5 reported a significant association between breastfeeding knowledge and attitude $(\mathrm{p}<0.00)$ as well as breastfeeding knowledge and intention $(\mathrm{p}<0.00)$ of the respondents

\section{Discussion}

Breastfeeding decisions and practices have been reported to be greatly influenced by breastfeeding knowledge 
Table 4. Breastfeeding intention and attitude with intention category of female corpers.

\begin{tabular}{lcr}
\hline Variables & Frequency & Percent \\
\hline Do you think you know all it takes to breastfeed & & 35.9 \\
Yes & 164 & 64.1 \\
No & 293 & 55.4 \\
Do you think you are well prepared for breastfeeding & & 44.6 \\
$\quad$ Yes & 253 & \\
No & 204 & 90.6 \\
Will you breastfeed your child later in the future & & 9.4 \\
Yes & 414 & \\
No & 43 &
\end{tabular}

If yes, how will you breastfeed your child? $(n=414)$

At mothers will $\quad 36$

As baby demands

As scheduled by mother

Intended time to introduce breast milk to child

Within 1 hour of birth

After 1 hour of delivery

Day 2 and above

Yet to decide

Intended age to introduce water to child

Before 6 month of age $\quad 152$

6 months and above

Yet to decide

Median age $=4$ months

Intended age to introduce complementary food

Less than 6 months

6 - 11 months

12 months and above

Yet to decide

Intention to breastfeed exclusively

Yes 
Table 5. Breastfeeding knowledge, attitude and intention relationship.

\begin{tabular}{|c|c|c|c|c|c|}
\hline & & \multicolumn{2}{|c|}{ Knowledge } & \multirow[b]{2}{*}{$\chi^{2}$} & \multirow[b]{2}{*}{ P value } \\
\hline & & Poor knowledge N (\%) & Good knowledge N (\%) & & \\
\hline \multirow{2}{*}{ Attitude } & Negative attitude & $116(44.6)$ & $14(7.1)$ & \multirow{2}{*}{77.47} & \multirow{2}{*}{0.000} \\
\hline & Positive attitude & $144(55.4)$ & $183(92.9)$ & & \\
\hline \multirow{4}{*}{ Intention } & Total & $260(100.0)$ & $197(100.0)$ & \multirow{4}{*}{94.47} & \multirow{4}{*}{0.000} \\
\hline & Poor intention & $176(67.7)$ & $42(21.8)$ & & \\
\hline & Good intention & $84(32.3)$ & $154(78.2)$ & & \\
\hline & Total & $260(100.0)$ & $197(100.0)$ & & \\
\hline
\end{tabular}

and attitudes [17]-[20]. Evidence has shown that infant feeding decisions are highly dependent on maternal attitudes and intentions toward breastfeeding, which in turn, may be formed as early as adolescence [16] [21] and early adulthood. Exploring the breastfeeding knowledge, attitude and intention of young adult will help in planning and understanding the strategies that may be used in intervention program to this sub-population before they step into parenthood. This study however assessed breastfeeding knowledge, attitude and intention of Nigerian female young adults.

The findings from this study revealed that less than half of the respondents had good breastfeeding knowledge; this result is found to be similar what was reported among Korean undergraduates [15], Saudi Arabian young mothers [22] and Nigerian female students [23]. However, contrast findings were reported among female undergraduates in United States [13] Hong Kong [24] China [14] where the most of the respondents had relatively good and moderate breastfeeding knowledge. Previous studies have reported Nigerian women to have adequate knowledge towards breastfeeding [25]-[29] comparing this findings with the findings from the current study, there is a likelihood of decline in the proportion of Nigerian women with adequate breastfeeding knowledge in the nearest future and this may further reduce optimum breastfeeding practices among Nigerian mothers.

The first hour of an infant's life is of great importance for the initiation and continuation of breastfeeding, it also to establish the emotional bond between mother and the baby [1], initiation of breastfeeding within an hour of birth was therefore recommended [1]. Delay in initiation of breastfeeding after the first hour has equally been reported to increase the risk of neonatal mortality, in particular neonatal deaths due to infections [30] [31]. The proportion of the young adults in this study with adequate knowledge of breastfeeding initiation was close to the percentage reported among mothers with post-secondary education with the actual initiation of breastfeeding within one hour of child birth in the recent national demographic and health survey [30]. Findings from this study align with similar studies among US adolescents [13] and Tanzanian young mothers [32] but not in conformity with what was reported among female undergraduates in Mainland China [14]. According to Wen and colleagues [33], mothers who had completed tertiary education were more likely to be aware of the breastfeeding recommendation than those who had school certificate or less. In this study, an appreciable number of the respondents knew the correct definition of exclusive breastfeeding and were aware that only breastmilk is sufficient for infants in the first 6 months. This is in line with the study of Lou and colleagues [14].

The crucial role of colostrum from a mother breast as the first immunization a baby received after delivery has been proven by researchers [34] [35]. Findings however from this study indicate poor knowledge of colostrum among the female young adult in Ibadan. In a study among mothers to-be in Saudi Arabia, $67.1 \%$ students were unaware of the importance of colostrum [36]. Also in a related study among female undergraduates in Nigeria [37], majority of the respondents reported their lack of knowledge on the immunological protection of colostrum. These findings on wrong description of colostrum are similar to what was obtained among the young adult in the current study. In a study among first-time mothers in China [38], it was reported that almost all mothers (99\%) knew breastfeeding was good for the baby's health, while $22 \%$ of mothers did not think breastfeeding was beneficial to the mother's health. From the current study, it was found that majority of the young adults reported their awareness of the benefit of breastfeeding to both the mother and the infant.

Decision to breastfeed has been reported to be highly dependent on the attitude towards breastfeeding, which are probably formed as early as adolescence [21] and also in early adulthood. It was also reported that positive 
parental attitudes towards infant feeding are important component in ensuring optimum child nutritional health [39]. This may be as a result of a positive relationship between attitude and optimum practices. About half of the respondents from this study had positive attitude towards breastfeeding. Studies have however found a form of association between positive attitude towards breastfeeding and optimal infant feeding practices especially breastfeeding [25] [40]-[42]. Contrast to our study, majority of mothers to-be in Saudi Arabia were reported to have positive attitude towards breastfeeding [36]. Other studies have also established that older students show positive attitude towards breastfeeding [7] [13].

Several studies have reported a wide variation in the acceptability of public breastfeeding among members of similar populations [14] [18] [43]-[45]. It is noteworthy to report that the attitudinal response of young adult in the current study towards discouragement of breastfeeding in the public was low.

The acceptability of breastfeeding in the public among young adult in this study is higher than what was obtained among the young adult in China [14]. Studies have reported mothers' hesitation to breastfeeding their babies as a result of their concern on insufficient supply of breastmilk [33] [46] [47]. In the current study, about half of the respondents had a positive attitude to sufficiency of breastmilk for infants in the first 6 months of life. Previous studies have reported female young adults to disagree with the common notion that women with small breasts cannot make enough breast milk [14] [15]. It is also encouraging to note the positive attitudinal response of the respondents from this study towards the amount of breastmilk produced not being determined by the size of the breast.

Actual breastfeeding practices of mothers have been associated with their breastfeeding intentions before birth [48] [49]. Participants in the current study generally demonstrated poor breastfeeding intention. Studies have repeatedly found that women's pre-birth breastfeeding intentions are a good predictor of the actual duration of breastfeeding [49] [50]. Ninety percent of the participants expressed their intention to breastfeed in the future. This percentage is higher than that of the female undergraduates [13] and female adolescents [43] in USA, as well as Hong Kong female university students [24].

It is important to note that majority of the study respondents intended to breastfeed in the future, only about one-third of the respondents revealed to know all it requires to breastfeed their future children while about half reported to have been prepared for breastfeeding. In a study by Wen et al., [33] majority of the respondents in their study plan to initiate breastfeeding within the first hour of birth, this is in contrast to the current study where only about half of the respondent intended to initiate breastfeeding with one hour of birth while about one-fifth was yet to decide. A recent study among undergraduates in Nigeria reported a higher proportion (65\%) of its responded intending to initiate breastfeeding in the first 6 hour of birth [37], this result is however not in line with the WHO recommendation of initiation within one hour of birth. This study further disclosed that young adults were fairly aware of breastfeeding and its benefit in relation to both the mother and child. According to Wen et al., [33] the main reasons given by the mothers for planning to breastfeed was as a result of their understanding of health benefit of breastfeeding to both the mother and the child. Findings from this study is similar to what was obtained among First-Time Mothers in China [38] where majority of expectant mothers planned to breastfeed their babies while more than half of mothers planned to exclusively breastfeed their babies.

Studies have established that the intention to breastfeed is a strong predictor for actual initiation and duration of breastfeeding [8] [48] [49] [51]. Addressing mothers' awareness and intention to breastfeed has been reported to improve breastfeeding practice [38] [48], however addressing this issue prior to motherhood especially in early adolescence and early adulthood is deem important and will go a long way in improving the eventual practice in motherhood. Breastfeeding knowledge of young adults and adolescents has previously been associated with breastfeeding attitude and intention in relation to other studies [13] [43] [45] [51]-[53] our study found significant association between breastfeeding knowledge and attitude as well as intention.

\section{Conclusion}

Findings from this study have provided us with information on breastfeeding knowledge, attitude and intention among future Nigerian mothers. Although we reported a relatively good breastfeeding knowledge and averagely positive attitude however their breastfeeding intention was poor. Improving the knowledge and attitude of the female young adults towards breastfeeding will influence a positive breastfeeding intention hence increase the likelihood of optimum breastfeeding among future mothers. It is therefore recommended that this intervention 
should be targeted on ensuring adequate breastfeeding knowledge and good breastfeeding intention.

\section{Acknowledgements}

The authors wish to acknowledge the Oyo State secretariat of the National Youth Service Corps' for granting the permission and access to the members of NYSC serving in the state.

\section{Declaration of Conflict of Interests}

The authors declared no potential conflicts of interest pertaining the research, authorship and publication of this article.

\section{References}

[1] World Health Organization (2003) Global Strategy for Infant and Young Child Feeding. Geneva. http://www.who.int/nut/documents/gs-infant-feeding-text-eng-pdf

[2] Molbak, K., Gottschau, A., Aaby, P., Hojlyng, N., Ingholt, L. and Da Silva, A.P.J. (1994) Prolong Breastfeeding, Diarrhoeal Disease, and Survival of Children in Guinea-Bissau. British Medical Journal, 308, 1403-1406. http://dx.doi.org/10.1136/bmj.308.6941.1403

[3] WHO (2001) WHO Collaborative Study Team on the Role of Breastfeeding on the Prevention of Infant Mortality: Effect of Breastfeeding on Infant and Child Mortality Due to Infectious Diseases in Less Developed Countries: A Pooled Analysis. Lancet, 355, 451-455.

[4] Patricia, M.J. (2001) The Effect of Breastfeeding Education on Adolescent Beliefs and Attitudes: A Randomized School Intervention in the Canadian Ojibwa Community of Sagkeeng. Journal of Human Lactation, 17, $245-255$.

[5] Wing, J. (2012) "Youth” Windsor Review. Journal of the Arts, 45, 9.

[6] Eyitope, A.O. (2014) Sexual Behaviour and Risk Perception for HIV among Youth Attending the National Youth Service Camp, Ede, Osun State, Nigeria. Journal of Health Science, 4, 1-6.

[7] Sonia, M., Nancy, V.-H. and Jeffrey, H. (2008) Attitudes, Knowledge, and Intentions Related to Breastfeeding among University Undergraduate Women and Men. Journal of Human Lactation, 24, 186-192.

[8] Shahla M., Kathleen, F. and Ashley, K. (2010) Factors That Positively Influence Breastfeeding Duration to 6 Months: A Literature Review. Journal of Women and Birth, 23, 135-145. http://dx.doi.org/10.1016/j.wombi.2010.02.002

[9] Hila, S.J. (2006) Baccalaureate Nursing Students’ Breastfeeding Knowledge: A Descriptive Survey. Nurse Education Today, 26, 332-337. http://dx.doi.org/10.1016/j.nedt.2005.10.014

[10] Nesbitt, S., Campbell, K., Jack, S., Robinson, H., Piehl, K. and Bogdan, J. (2012) Canadian Adolescent Mothers’ Perceptions of Influences on Breastfeeding Decisions: A Qualitative Descriptive Study. BMC Pregnancy and Childbirth, 12, 149. http://dx.doi.org/10.1186/1471-2393-12-149

[11] Lynn, A., Florence, M., Nazarius, T.M., Johansson, A., Edward, K.K. and Elisabeth, F. (2008) Adolescent and Adult First Time Mothers' Health Seeking Practices during Pregnancy and Early Motherhood in Wakiso District, Central Uganda. Reproductive Health Journal, 5, 13.

[12] Anjum, Q., Ashfaq, T. and Siddiqui, H. (2007) Knowledge regarding Breastfeeding Practices among Medical Students of Ziauddin University Karachi. Journal of Pakistan Medical Association, 57, 480-483.

[13] Katherine, K.F., Lou, Z.X., Jennifer, N.C., Mona, H.F. and Lee, M.T. (2012) Breastfeeding Knowledge, Attitudes, Prior Exposure, and Intent among Undergraduate Students. Journal of Human Lactation, 28, 556-564. http://dx.doi.org/10.1177/0890334412446798

[14] Lou, Z.X., Guo, Z., Med, M., John, O.G., Huang, L.J., Liu, F., Pang, X.H. and Katherine, K.F. (2014) Breastfeeding Knowledge, Attitudes, and Intention in a Sample of Undergraduate Students in Mainland China. Journal of Human Lactation, 30, 331-339. http://dx.doi.org/10.1177/0890334414526058

[15] Nam-Mi, K., Song, Y. and Ima, E.-O. (2005) Korean University Students’ Knowledge and Attitudes toward Breastfeeding: A Questionnaire Survey. International Journal of Nursing Studies, 42, 863-870. http://dx.doi.org/10.1016/j.ijnurstu.2005.01.003

[16] Haya, H., Naja, F., Keyrouz, S., Hwalla, N., Karam, J., Al-Rustom, L. and Nasreddine, L. (2014) Breastfeeding Knowledge, Attitude, Perceived Behavior, and Intention among Female Undergraduate University Students in the Middle East: The Case of Lebanon and Syria. Food and Nutrition Bulletin, 35, 179-190.

[17] Chambers, J.A., Mclnnes, R.J., Hoddinott, P. and Alder, E.M. (2007) A Systematic Review of Measures Assessing Mothers' Knowledge, Attitudes, Confidence and Satisfaction towards Breastfeeding. Breastfeeding Review, 15, 17-25. 
[18] Papinczak, T.A. and Turner, C.T. (2000) An Analysis of Personal and Social Factors Influencing Initiation and Duration of Breastfeeding in a Large Queensland Maternity Hospital. Breastfeeding Review, 8, 25-33.

[19] Kong, S.K.F. and Lee, D.T.E. (2004) Factors Influencing Decision to Breastfeed. Journal of Advanced Nursing, 46, 369-379. http://dx.doi.org/10.1111/j.1365-2648.2004.03003.x

[20] Chezem, J., Friesen, C. and Boettcher, J. (2003) Breastfeeding Knowledge, Breastfeeding Confidence, and Infant Feeding Plans: Effects on Actual Feeding Practices. Journal of Obstetric, Gynecologic, \& Neonatal Nursing, 32, 40-47. http://dx.doi.org/10.1177/0884217502239799

[21] Leclair, E., Robert, N., Sprague, A.E. and Fleming, N. (2015) Factors Associated with Breastfeeding Initiation in Adolescent Pregnancies: A Cohort Study. Journal of Pediatric and Adolescent Gynecology, 28, 516-521. http://dx.doi.org/10.1016/j.jpag.2015.03.007

[22] Hala, S., Afaf, M., Afnan, S. and Wadaa, A.A. (2013) Breastfeeding Knowledge, Attitude and Barriers among Saudi Women in Riyadh. Journal of Natural Sciences Research, 3, 6-14.

[23] Ojofeitimi, E.O., Owolabi, O.O., Eni-Olorunda, J.T., Adesina, O.F. and Esimai, O.A. (2001) Promotion of Exclusive Breastfeeding (EBF): The Need to Focus on the Adolescents. Journal of Nutrition Health, 15, 55-62. http://dx.doi.org/10.1177/026010600101500107

[24] Marie, T. and Joan, D.E. (2007) Knowledge, Attitudes, Exposure, and Future Intentions of Hong Kong University Students toward Infant Feeding. Journal of Obstetric, Gynecologic, \& Neonatal Nursing, 36, 243-254. http://dx.doi.org/10.1111/j.1552-6909.2007.00144.x

[25] Mbada, C.E., Olowookere, A.E., Faronbi, J.O., Oyinlola-Aromolaran, F.C., Faremi, F.A., Ogundele, A.O., Awotidebe, T.O., Ojo, A.A. and Oluwakemi, A. (2013) Augustine. BMC Research Notes, 6, 552.

[26] Agu, U. and Agu, M.C. (2011) Knowledge and Practice of Exclusive Breastfeeding among Mothers in a Rural Population in South Eastern Nigeria. Tropical Journal of Medical Research, 15, 39-44.

[27] Oche, M.O., Umar, A.S. and Ahmed, H. (2011) Knowledge and Practice of Exclusive Breastfeeding in Kware, Nigeria. African Health Sciences, 11, 518-523.

[28] Ekanem, I.A., Ekanem, A.P., Asuquo, A. and Eyo, V.O. (2012) Attitude of Working Mothers to Exclusive Breastfeeding in Calabar Municipality, Cross River State, Nigeria. Journal of Food Research, 1, 71-75. http://dx.doi.org/10.5539/jfr.v1n2p71

[29] Ukegbu, A.U., Ukegbu, P.O., Onyeonoro, U.U. and Ubajaka, C.F. (2011) Determinants of Breastfeeding Patterns among Mothers in Anambra State, Nigeria. SAJCH, 5, 112-116.

[30] National Population Commission (NPC) (Nigeria) and ICF International (2014) Nigeria Demographic and Health Survey 2013. NPC and ICF International, Abuja and Rockville.

[31] World Health Organization Library Cataloguing-in-Publication Data (2012) Essential Nutrition Actions: Improving Maternal, Newborn, Infant and Young Child Health and Nutrition.

[32] Hadijah, M.A., Cath, C. and Von Pamela, H. (2013) Exclusive Breastfeeding: Mothers' Awareness and Healthcare Providers' Practices during Antenatal Visits in Mvomero, Tanzania. International Journal of Nutrition and Metabolism, 5, 40-49.

[33] Wen, L.M., Baur, L.A., Rissel, C., Alperstein, G. and Simpson, J.M. (2009) Intention to Breastfeed and Awareness of Health Recommendations: Findings from First Time Mothers in Southwest Sydney, Australia. International Breastfeeding Journal, 4, 9. http://dx.doi.org/10.1186/1746-4358-4-9

[34] Tesfaye, S., Mulusew, G. and Tefera, B. (2011) Determinants of Timely Initiation of Breastfeeding among Mothers in Goba Woreda, South East Ethiopia: A Cross Sectional Study. BMC Public Health, 11, 217.

[35] Mahdi, A.H.A. (2013) Pregnant Revisions Information Centre for Maternal and Child Welfare in the Baghdad City about Benefit about Colostrum toward the New Born Baby. Mosul Journal of Nursing, 1, 4 p.

[36] Rasheed, P. (1994) Perception of Infant Feeding Practices among Mothers-to-Be: An Urban-Based School Study. Family and Community Medicine, 1, 72-78.

[37] Ogunba, B.O. and Agwo, E.O. (2014) Knowledge, Attitude and Intending Practice of Female Undergraduates about Breastfeeding. African Journal of Food Agriculture, Nutrition and Development, 14, 9039-9054.

[38] Jiang, H., Li, M., Yang, D.L., Wen, L.M., Hunter, C., He, G.S. and Qian, X. (2012) Awareness, Intention, and Needs regarding Breastfeeding: Findings from First-Time Mothers in Shanghai, China. Breastfeeding Medicine, 7, 526-534. http://dx.doi.org/10.1089/bfm.2011.0124

[39] Wojcicki, J.M., Gugig, R., Tran, C., Kathiravan, S., Holbrook, K. and Heyman, M.B. (2010) Early Exclusive Breastfeeding and Maternal Attitudes towards Infant Feeding in a Population of New Mothers in San Francisco, California. Breastfeeding Medicine, 5, 9-15. http://dx.doi.org/10.1089/bfm.2009.0003

[40] Kloeblen-Tarver, A.S., Thompson, N.J. and Miner, K.R. (2002) Intent to Breast-Feed: The Impact of Attitudes, Norms, 
Parity and Experience. American Journal of Health Behavior, 26, 182-187. http://dx.doi.org/10.5993/AJHB.26.3.3

[41] Hurley, K.M., Black, M.M., Papas, M.A., et al. (2008) Variation in Breastfeeding Behaviours, Perceptions, and Experiences by Race/Ethnicity among a Low-Income Statewide Sample of Special Supplemental Nutrition Program for Women, Infants and Children (WIC) Participants in the United States. Maternal \& Child Nutrition, 4, 95-105. http://dx.doi.org/10.1111/j.1740-8709.2007.00105.x

[42] Persad, M.D. and Mensinger, J.L. (2008) Maternal Breastfeeding Attitudes: Association with Breastfeeding Intent and Socio-Demographics among Urban Primiparas. Journal of Community Health, 33, 53-60. http://dx.doi.org/10.1007/s10900-007-9068-2

[43] Leffler, D. (2000) US High School Age Girls May Be Receptive to Breastfeeding Promotion. Journal of Human Lactation, 16, 36-40. http://dx.doi.org/10.1177/089033440001600107

[44] Fairbrother, N. and Stranger-Ross, I. (2010) Reproductive-Aged Women's Knowledge and Attitudes regarding InfantFeeding Practices: An Experimental Evaluation. Journal of Community Health, 26, 157-167. http://dx.doi.org/10.1177/0890334409352853

[45] O’Keefe, T.D., Henle, S.J. and Anderson, C.M. (1998) Breastfeeding on Campus: Personal Experiences, Beliefs, and Attitudes of the University Community. Journal of the American College Health, 47, 129-134. http://dx.doi.org/10.1080/07448489809595633

[46] Li, R., Fein, S.B., Chen, J. and Grummer-Strawn, L.M. (2008) Why Mothers Stop Breastfeeding: Mothers' Self-Reported Reasons for Stopping during the First Year. Pediatrics, 122, S69-S76. http://dx.doi.org/10.1542/peds.2008-1315i

[47] Bunik, M., Shobe, P., O’Connor, M.E., Beaty, B., Langendoerfer, S., Crane, L. and Kempe, A. (2010) Are 2 Weeks of Daily Breastfeeding Support Insufficient to Overcome the Influences of Formula? Academic Pediatrics, 10, 21-28. http://dx.doi.org/10.1016/j.acap.2009.09.014

[48] Forster, D.A., McLachlan, H.L. and Lumley, J. (2006) Factors Associated with Breastfeeding at Six Months Postpartum in a Group of Australian Women. International Breastfeeding Journal, 1, 18. http://dx.doi.org/10.1186/1746-4358-1-18

[49] Donath, S. and Amir, L.H., ALSPAC Study Team (2003) Relationship between Prenatal Infant Feeding Intention and Initiation and Duration of Breastfeeding: A Cohort Study. Acta Paediatrica, 92, 352-356. http://dx.doi.org/10.1111/j.1651-2227.2003.tb00558.x

[50] Gartner, L.M., Morton, J., Lawrence, R.A., Naylor, A.J., O’Hare, D. and Eidelman, A.I. (2005) Breastfeeding and the Use of Human Milk. Pediatrics, 115, 496-506. http://dx.doi.org/10.1542/peds.2004-2491

[51] Rempel, L.A. (2004) Factors Influencing the Breastfeeding Decisions of Long-Term Breastfeeders. Journal of Human Lactation, 20, 306-317. http://dx.doi.org/10.1177/0890334404266969

[52] Gile, M., Connor, S., McClenahan, C., Mallett, J., Stewart-Knox, B. and Wright, M. (2007) Measuring Young People’s Attitudes to Breastfeeding Using the Theory of Planned Behaviour. Journal of Public Health, 29, 17-26. http://dx.doi.org/10.1093/pubmed/fdl083

[53] Goulet, C., Lampron, A., Marcil, I. and Ross, L. (2003) Attitudes and Subjective Norms of Male and Female Adolescents toward Breastfeeding. Journal of Human Lactation, 19, 402-410. http://dx.doi.org/10.1177/0890334403258337 